\title{
OCORRÊNCIA DE CRYPTOSPORIDIUM SPP. EM PSITACÍDEOS MANTIDOS EM CATIVEIRO NAS REGIÕES SUL E SUDESTE DO BRASIL
}

\author{
PREVALENCE OF CRYPTOSPORIDIUM SPP. IN CAPTIVITY PARROTS FROM \\ SOUTH AND SOUTHEAST REGIONS OF BRAZIL
}

E. D. FERRARI ${ }^{1 *}$, B. N. SANTANA ${ }^{1}$, A. A. NAKAMURA ${ }^{1}$, M. F. C. PANEGOSSI ${ }^{1}$, K. D. S. BRESCIANI ${ }^{1}$, M. V. MEIRELES ${ }^{1}$

\section{RESUMO}

A criptosporidiose já foi descrita em várias espécies animais, incluindo 152 espécies de mamíferos e mais de 30 espécies de aves. A infecção em seres humanos tem sido relatada em mais de 90 países localizados em seis continentes. Apesar de não haver consenso para classificação definitiva das espécies de Cryptosporidium, alguns autores sugerem a existência de, pelo menos, 27 espécies. O presente trabalho tem como objetivo determinar a ocorrência de Cryptosporidium spp. em psitacídeos mantidos em cativeiro nas regiões sul e sudeste do Brasil. Coletaram-se 159 amostras de fezes de nove gêneros de aves da ordem psitaciformes, provenientes de nove cidades e quatro estados, presentes no Campeonato de Ornitologia 2015 da Federação Ornitológica do Brasil (FOB), realizado em Itatiba/SP. As amostras foram colhidas no momento da recepção das aves, do fundo da gaiola, antes que houvesse contato direto ou indireto entre as aves e de forma a evitar contaminação cruzada entre amostras. A purificação e concentração dos oocistos foram realizadas por meio da técnica de centrífugo-flutuação em solução de Sheather e, para análise microscópica, utilizou-se a técnica de coloração negativa com verde malaquita. Forpus spp. foi o gênero de aves com maior número de amostras analisadas (50,31\%; 80/159) e de amostras positivas para Cryptosporidium spp. (70\%; 7/10). Santa Catarina e São Paulo foram os únicos estados com positividade. O estado com maior número de aves positivas foi São Paulo (90\%; 9/10), sendo que 50\% (5/10) dessas amostras eram da cidade de Jundiaí e provenientes do mesmo proprietário. A ocorrência de Cryptosporidium spp. em psitacídeos mantidos em cativeiro nas regiões sul e sudeste do Brasil foi de 6,29\% (10/159), indicando que o parasito está presente nessas regiões e que psitaciformes, além de possivelmente apresentarem enfermidade clínica, podem também ser uma fonte de infecção para humanos e outras aves.

PALAVRAS-CHAVE: ENDOPARASITOSE. PSITACIFORMES. DIAGNÓSTICO MICROSCÓPICO.

ÁREA TEMÁTICA: Doenças Parasitárias

\footnotetext{
${ }^{1}$ Faculdade de Medicina Veterinária de Araçatuba (UNESP) - Câmpus de Araçatuba

* elisd.ferrari@yahoo.com.br
} 